\title{
An Easy to Use Open Source Authoring Tool to Create Effective and Reusable Learning Objects
}

\author{
ALDO GORDILLO, ENRIQUE BARRA, JUAN QUEMADA
}

\begin{abstract}
Authoring tools play a crucial role in the development of learning content facilitating the creation of Learning Objects. However, not much work has been done in order to determine if educators actually can use these tools to create effective and reusable Leaming Objects in an easy way. This paper address this issue by presenting and evaluating an open source authoring tool called ViSH Editor. Three factors were evaluated: the usability and user acceptance of the authoring tool, the quality and learning effectiveness of the created Learning Objects, and the reusability of these resources. Usability was evaluated through a lab test and the user acceptance with a survey among 180 users. Quality evaluation was conducted using LORI (Learning Object Review Instrument). The learning effectiveness was evaluated through learner surveys and test scores. Finally, reusability was evaluated by using the LORI instrument, by measuring metadata quality using a set of metrics, and by a quantitative analysis of reuse. Results show that ViSH Editor is an authoring tool capable of allowing educators to create effective and reusable Learning Objects in an easy way.
\end{abstract}

\section{INTRODUCTION}

Learning Objects have emerged in recent years as a key strategy for creating, sharing, and delivering learning resources. The fundamental idea behind Learning Objects is that educational content can be broken down into small chunks that can be independently created and reused in various contexts and e-Learning systems [1]. The main aim of Learning Objects is to improve reusability in order to minimize the production cost, save time, and enhance the quality of the educational resources. Significant discussion has been devoted to establishing a unifying definition of Learning Objects across the last years without reaching a consensus [2]. In this work we define Learning Objects as "reusable digital resources tagged with metadata that are selfcontained and that can be used for education." The multiple benefits of using Learning Objects have been exposed by several empirical investigations that have examined their instructional effectiveness and learning outcomes across different educational environments [3-5] as well as their capacity to be reused [6,7].

There are still some barriers hampering the use and adoption of Learning Objects in education. First, although there are several Learning Object Repositories publicly available on the Web such as MERLOT or Connexions, teachers find it difficult to locate suitable Learning Objects. Many teachers perceive the search process as time consuming and they can need over an hour to find an appropriate resource [8].

To alleviate this problem Learning Object Repositories usually adopt measures such as the use of ranking metrics [9] or recommender systems [10]. Although these measures can speed up the search process, teachers usually need to customize the Learning Objects they find to adapt them to their needs [11]. Besides, the low availability of topic specific Learning Objects is another barrier [5]. One way to solve all these problems is to allow teachers to create their own Learning Objects. However, the creation of Learning Objects is a highly technical and time consuming task. A solution to this issue is the use of authoring tools that allow educators to create effective Learning Objects with little effort and low cost without requiring them any programming knowledge or strong computer skills. A trained author can achieve a ratio of around $4 \mathrm{~h}$ of authoring to produce $1 \mathrm{~h}$ of 
instruction using an authoring tool and importing existing materials, while the creation of the same type of learning resource without using the tool is estimated to take between 300 and $1000 \mathrm{~h}$ per hour of instruction [12]. For an authoring tool to achieve an easy, fast, and effective creation process is essential to reuse existing resources and therefore, it would be advisable the adoption of the Learning Object strategy. The success of this strategy for creating Learning Objects through an authoring tool will depend on three key factors:

(1) The usability and user acceptance of the authoring tool. Educators need to create the Learning Objects in an easy and pleasant way even if they have little computer skills.

(2) The quality and learning effectiveness of the created Learning Objects. The Learning Objects created with the authoring tool should be well designed, achieve high user acceptance, and be effective in terms of learner engagement and academic performance.

(3) The capacity of the created Learning Objects to be reused and shared. Authoring tools based on the Learning Object approach need to go beyond creating effective learning resources in an easy way. They need to be able to generate these resources in a way they can be easily reused in different e-Learning systems and educational environments. Besides, an authoring tool that aims to create open Learning Objects should facilitate their sharing and discoverability.

Moreover, according to [13], an authoring tool should not only be easy to use and produce Learning Objects with good quality and high reusability but also be distributed under an open source license to allow its customization. Open source software has many advantages and offer several benefits for open education in comparison to proprietary software [14].

There are some works about open source Learning Object authoring tools in the literature [15-24], but none of them have performed an evaluation covering the aforementioned three key factors. Therefore, further research is required to determine if educators actually can use Learning Object authoring tools to create effective and reusable Learning Objects in an easy way.

This paper presents an easy to use and open source Learning Object authoring tool called ViSH Editor to facilitate the creation of effective and reusable Learning Objects. It contributes to the state of the art of open source authoring tools for creating Learning Objects by describing a tool with novel and distinguishing features and providing a complete evaluation. The paper explores the following research question: Is ViSH Editor an authoring tool capable of allowing educators to create effective and reusable Learning Objects in an easy way? In order to address this question, the three key factors were evaluated: the usability and user acceptance of the authoring tool, the quality and learning effectiveness of the created Learning Objects, and the reusability of these resources.

The paper is organized as follows. Next section reviews related work of e-Learning authoring tools with emphasis on open source tools for creating Learning Objects. Section Overview of ViSH Editor describes the main characteristics of ViSH Editor. The following section explains the methodology. Sections Evaluation of the Authoring Tool, Evaluation of the Created Learning Objects, and Reusability Evaluation of the Created Learning Objects show, respectively the results of the evaluations of the first, second, and third factor. Finally, last section finishes with the conclusions of the study and future work.

\section{RELATED WORK}

An e-Learning authoring tool can be defined as "a software application that enables authors to create complete educational resources or courseware by integrating and linking together different objects and custom content generated by them." These systems are usually designed for users with basic computer skills although some of them also allow the use of programming languages. Their main goals are to save cost and effort. There is no standard classification system for authoring tools although there has been some attempts such as [25], which proposed and evaluated a taxonomy for classifying these systems into three major groups: content development tools, multimedia tools, and auxiliary tools. Some works like [26] have examined the different characteristics of authoring tools. The most important characteristic of an authoring tool is the type of resource or output that can be created with it. Authoring tools have been primarily used in education for creating Learning Objects and e-Learning resources in general [15-23,27-35]. Nevertheless, authoring tools have been also used for other purposes such as authoring educational metadata [36], developing metadata application profiles [37], creating learning designs [19], planning courses [38], and collaborative learning scenarios [39], generating exams [40], adding virtual contents into printed educational materials [35], or simulating digital circuits [41]. This work focuses on Learning Object authoring tools. Other relevant characteristics of these tools are among others: platform support, media and files type support, content customization, automated programming, ease of use, creative freedom, adherence to e-Learning standards, reusability of the created resources, extensibility, cost, and license. There are some studies that have confirmed that Learning Objects created with authoring tools are able to improve learning outcomes and enhance student engagement $[12,34,35,42]$. Learning Object authoring tools have been also adopted by repositories since educational communities can use them for creating corpora of learning resources $[27,43]$. These tools have been also used with the main aim of stimulating learning by doing and enhancing learner skills such as creativity, critical thinking, and problem solving [44]. Moreover, Learning Object authoring tools can help traditional e-Learning systems to integrate features from Knowledge Management Systems, since they allow creating highly reusable knowledge resources in the form of Learning Objects that can be later shared, adapted, and integrated in other Learning Objects [45].

Many Learning Object authoring tools have been developed over the last years. Most of them are proprietary software such as Adobe Captivate, Articulate Presenter, Articulate Quizmaker, CourseLab, Microsoft LCDS, or HotPotatoes. However, there are also open source alternatives such as eXeLearning [29], JClic [30], RELOAD Editor [31], RELOAD Learning Design Editor [19,31], Xerte [21,32], or GLO Maker [16]. There are some works related to open source Learning Object authoring tools in the literature, but more research is needed in this area since there is a lack of evaluation studies of this kind of tools. In [13], six authoring tools (eXeLearning, Xerte, CourseLab, HotPotatoes, MyUdutu, and Microsoft LCDS) for creating Learning Objects were evaluated according to two criteria: usability of the tools and quality of the produced Learning Objects. Usability evaluation was carried out by one single evaluator using Nielsen's heuristics while the quality of the Learning Objects was measured by comparing them with a reference Learning Object produced by a professional. The study concluded that both proprietary and open source authoring tools 
can be used for producing good quality Learning Objects. Nevertheless, these results are quite limited and authors request for further research because the evaluation only involved one evaluator and one Learning Object. Another related work can be found in [24], which presents a user-centred usability evaluation of three authoring tools: GLO Maker, Microsoft LCDS, and Course Lab. A user testing in which six users performed 16 tasks with each tool was conducted in order to analyze the ease of use and user satisfaction of the authoring tools. In addition to the qualitative evaluation through questionnaires, task success rates, and completion times were measured. Based on the results, authors stated that users can easily use GLO Maker for creating Learning Objects. A use case of the JClic authoring tool in the medical field is described in [20] but no evaluation is provided. In other study [22], 71 students used and rated the effectiveness and usability of one Learning Object created with the eXeLearning authoring tool. Nonetheless, the tool was not evaluated and the results are severely limited due to the small sample size of one Learning Object. An evaluation of the eXeLearning tool was carried out in [23], where a group of 33 students used the tool for creating 10 Learning Objects. The students used questionnaires to rate the usability of eXeLearning and the usability, content quality and effectiveness of the created resources. Results showed that most respondents found eXeLearning easy to use and that they had good opinion about the created Learning Objects. This evaluation was merely qualitative and the rating of the resources was not performed in a real situation. There are more related works that describe other open source Learning Object authoring tools such as LO Creator [15] or LOC Tool [17], but no evaluation is provided.

Finally, there are works that have studied the Learning Object reuse in different repositories. Ochoa [6] conducted a quantitative analysis of reuse in the ARIADNE repository which showed that $11.5 \%$ of their Learning Objects were reused for authoring new ones. This same study showed that $22.6 \%$ of the Learning Objects available in the Connexions repository were reused to form collections. A similar study can be found in [7], where the Learning Object reuse in the LRE repository was analyzed showing that around $19 \%$ of the resources were reused in collections.

\section{OVERVIEW OF VISH EDITOR}

ViSH Editor is a web-based open source authoring tool that aims to facilitate the creation of effective and reusable Learning Objects. The tool is publicly available at http://vishub.org, the website of the ViSH e-Learning platform [46]. ViSH Editor has been used for more than 4 years in ViSH with considerable success. Hundreds of users have used ViSH Editor for authoring thousands of Learning Objects which are nowadays published in the ViSH platform. It is worth pointing out that ViSH Editor can be used to create Learning Objects about any topic. The ViSH community have used it to create resources to teach mathematics, physics, technology, computer science, biology, and history among other topics.

\section{System Architecture}

The system consists of two main components: an editor (ViSH Editor) and a player (ViSH Viewer). ViSH Editor is a client-server web application that allows creating Learning Objects and saving them in JSON format. ViSH Viewer is a fully client-side web application that allows displaying the Learning Objects created with ViSH Editor in a web browser and interacting with them.
Both applications have been developed in HTML 5 and can be used with just a web browser. The created Learning Objects can be accessed from any device with a HTML 5 compatible web browser without any installation being needed. The communication between the ViSH Editor client and the server is performed through an API. So, the tool is not tied to any specific backend technology and different server implementations can be developed for integrating the tool in different environments. The source code of ViSH Viewer and the client part of ViSH Editor is available at http://github.com/ging/vish_editor and a Ruby on Rails implementation of the server part of ViSH Editor is available at http://github.com/ging/vish. This implementation is the one used in the ViSH platform.

\section{Learning Object Model}

Learning Objects can be combined among them to build more complex ones forming a hierarchy where the different levels of the hierarchy are called aggregation or granularity levels. Learning Object models define these levels of granularity and specify how the components can be aggregated as well as their properties. The main Learning Objects that can be created with ViSH Editor are the Interactive Presentations, which consist of series of slides displayed in a certain sequence, where each of these slides can be created by the author using different types of resources. The Interactive Presentations are built according to the Learning Object model of ViSH Editor which defines four levels of granularity according to the Figure 1:

- The first level, which corresponds to the most granular or atomic level, includes raw media files like images, audios, videos, flash objects, and documents as well as other resources such as paragraphs of text, questions, and quizzes, websites and web applications (including SCORM and IMS CP packages).

- The second level has a single Learning Object called "slide" that consists of a collection of level one Learning Objects.

- The third level includes a series of Learning Objects termed "slidesets" which are built as a composition of slides. The current version of the tool allows creating three different slidesets: Flashcards, Virtual Tours, and Enriched Videos. Flashcards are "resources presented as an image background with 'hot zones' identified by animated arrows on which the learner can click to see additional contents that the author has previously linked". Virtual Tours are similar to Flashcards, but they are presented as interactive maps where the "hot zones" are places identified by map pins. Lastly, Enriched Videos are "videos augmented with other resources (e.g. questions, images, websites, etc.) which can be selected and customized by the author, and that can be displayed

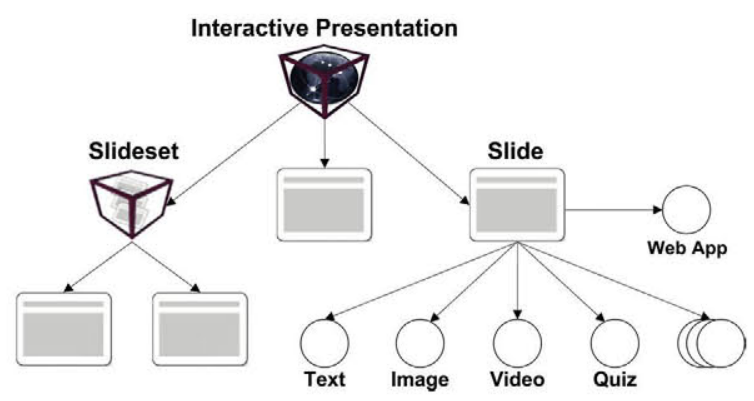

Figure 1 Learning Object model of ViSH Editor. 


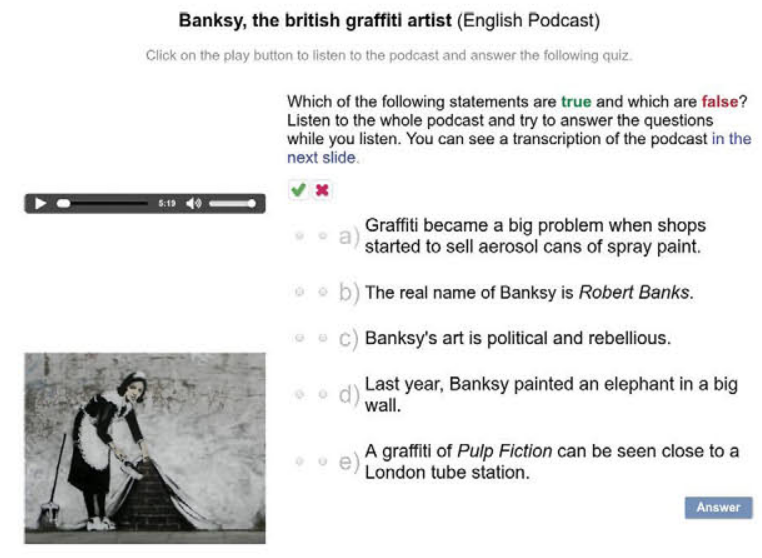

Figure 2 Learning Object created with ViSH Editor.

automatically when the video reaches a specific point of time or when the learner requests one of them explicitly by selecting it in the progress bar or in a side menu".

- The fourth and last level corresponds to the Interactive Presentations. These Learning Objects can contain Learning Objects of the third level or directly slides. Nevertheless, they cannot contain other Interactive Presentations although they can import the Learning Objects with which they are built. Figure 2 shows an example of an Interactive Presentation.

\section{Main Features}

ViSH Editor is based on the WYSIWYG (What You See Is What You Get) paradigm. It provides a user friendly interface where the
Learning Object to be created is presented as a presentation of slides, on which the authors can add new slides and move or remove the existing ones. Each slide is created from a template and inside it authors can create and insert the different types of contents. Figure 3 illustrates the user interface of ViSH Editor. The tool offers different themes which allow applying a predefined combination of colors, fonts, and effects such as slide transitions. Authors can preview the Interactive Presentations they are creating from a learner's perspective at any time. Interactive Presentations can be saved as drafts so they can be only accessed by their author until their publication. There are several videotutorials available for users to get started with the tool and learn how to use specific features. In addition, context-sensitive help is provided in the different sections of the user interface. ViSH Editor is internationalized and supports several languages such as English, Spanish, French, and German.

Authors can create paragraphs of text using a WYSIWYG rich text editor. They can also create different types of self-graded questions (multiple choice, true/false, short answer, sorting), and specify several settings for them such as the maximum number of attempts or the choices shuffling. An Audience Response System is available allowing teachers to pose a question and get instant feedback from the audience, which just need a device with a web browser to connect to the poll and answer the question. Besides creating contents from scratch, authors can insert many types of resources: pictures, audios, videos, flash objects, documents, websites, HTML5 applications, SCORM, and IMS CP packages, etc. These resources can be added via their URL, by uploading them or by searching on different educational repositories and content providers such as ViSH, Europeana, LRE, Flickr, YouTube, or SoundCloud. When authors upload their videos and audios to the server they are converted to HTML5 compliant

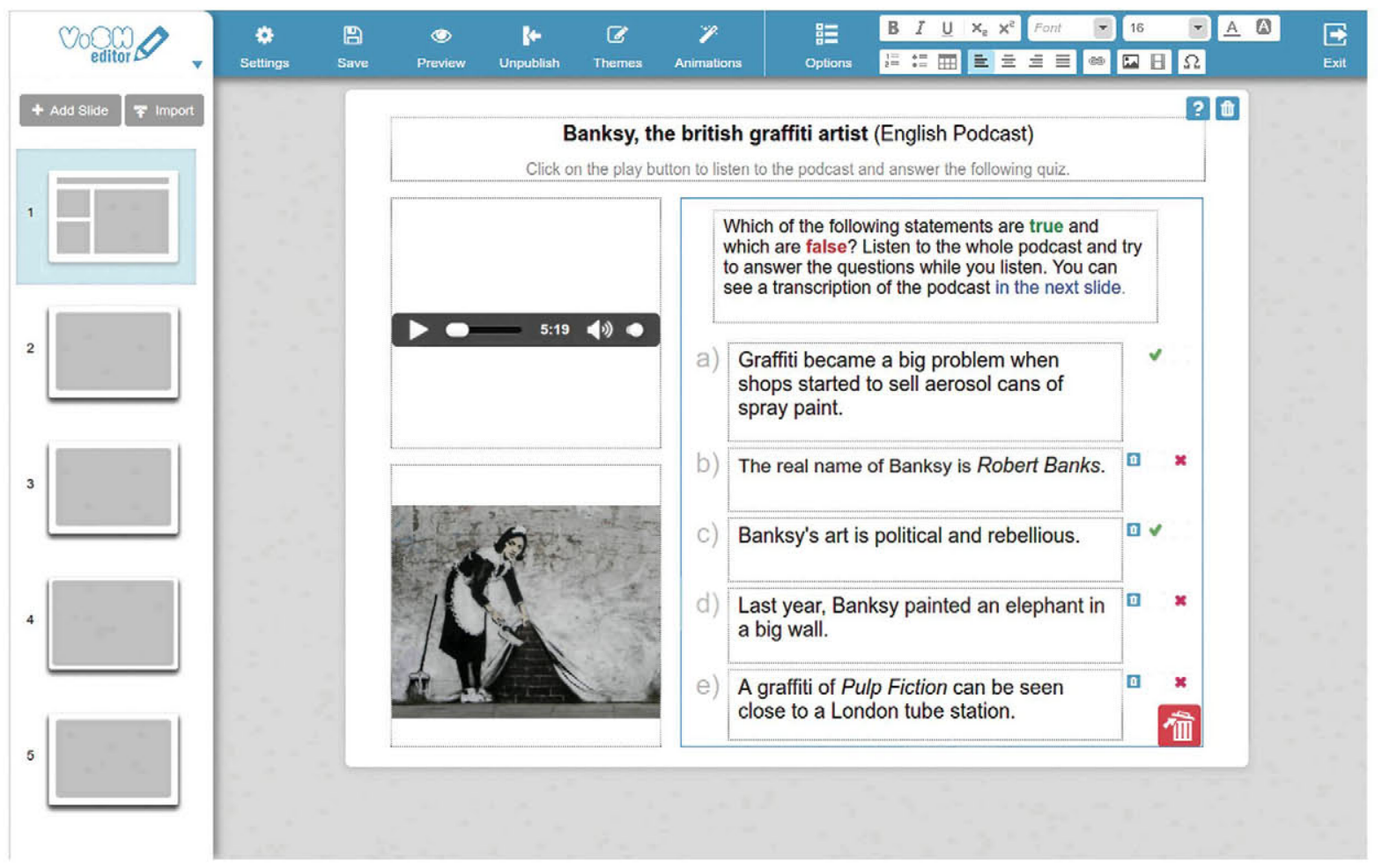

Figure 3 User interface of ViSH Editor. 
formats making them accessible from all browsers and devices. Authors can also create other interactive Learning Objects such as Flashcards, Virtual Tours, or Enriched Videos and integrate them in the Interactive Presentations. ViSH Editor also allows importing slides from PDF slideshows into the Interactive Presentations. This way, PDF slideshows can be quickly and easily converted to web Learning Objects which can be later enriched with more resources and contents. Authors can also import slides from other Interactive Presentations (created by them or by other users) retrieved from external files or web repositories. Moreover, IMS QTI, and Moodle XML questions can be imported from XML files. ViSH Editor enables the authors to fill the metadata of the Learning Object through the user interface. They can indicate several metadata elements such as title, description, author, language, keywords, context, and age range, difficulty, typical learning time, or educational objectives. Attachment files can be included to provide complementary materials such as usage recommendations or lesson plans. Authors can also specify a license for the Learning Object before publishing on the repository. They also have the possibility of specifying more options such as if the users will be allowed to comment on the Interactive Presentation after being published. Authors can reuse resources and slides of Interactive Presentations published by other users as well as create derivative works by cloning existing Interactive Presentations. Thereby, the tool can support collaboration among the members of a community.

Interactive Presentations created with ViSH Editor are saved in the repository in JSON format. However, they can be exported to the SCORM e-Learning standard enabling their integration in Virtual Learning Environments such as Moodle, Blackboard, or Sakai. The current version allows exporting to SCORM 1.2 and SCORM 2004 4th Edition. Metadata are included in the SCORM packages according to the LOM (Learning Object Metadata) standard. Conformance of SCORM packages was validated using the latest versions of ADL Conformance Test Suite. Interactive Presentations can be also exported as JSON files which can be opened by the editor tool. Furthermore, the created questions can be exported to IMS QTI and Moodle XML to be reused in other systems. Generated IMS QTI questions were validated using the official QTI online validator and Moodle questions were tested in different versions of Moodle. In addition to export the created Interactive Presentations to different formats, they can be shared through an URL or embedded in a website by using an embed code. An API is provided in all the Learning Objects created with ViSH Editor allowing third party web applications to communicate with the tool and handle the Interactive Presentations (e.g. advance slides) allowing this way more sophisticated integrations.

\section{Advanced Integration of Packaged Learning Objects}

The most distinguishing feature of ViSH Editor compared to other Learning Object authoring tools is the advanced integration of packaged Learning Objects. Authors can insert and integrate Learning Objects packaged or created according to different e-Learning standards as well as HTML5 web applications that do not adhere to any e-Learning specification into the Interactive Presentations they are creating. Thereby, authors can reuse and combine Learning Objects created with other authoring tools and e-Learning systems as well as learning resources obtained from digital repositories that follow some e-Learning specification. The current version of the tool allows integrating Learning Objects that adhere to the following standards: IMS QTI 2.1, Moodle XML 2.8,
IMS CP 1.1.4, SCORM 1.2, and SCORM 2004 4th Edition. Generic web applications can be also integrated allowing the reuse of the huge amount of tools and applications available on the Web and that are useful for education. Besides, e-Learning content developers can build and publish web applications for being used in Interactive Presentations. An API is provided to the developers in order to allow the integrated web applications to communicate with ViSH Editor and use advanced features (e.g. access to user data, grading, ...).

This integration does not only allow integrating the content of the packaged Learning Objects into the Interactive Presentations, it also manages the communication (if any) between the integrated Learning Objects and the Virtual Learning Environments so that the Interactive Presentations will behave as one single resource or activity in the eyes of the Virtual Learning Environments in which they are integrated.

\section{METHODOLOGY}

This paper addresses the following research question: Is ViSH Editor an authoring tool capable of allowing educators to create effective and reusable Learning Objects in an easy way?

In order to answer this question, the following three factors were evaluated:

(1) The usability and user acceptance of the authoring tool. First, in order to evaluate the usability of ViSH Editor, a lab test involving 12 participants was conducted. This lab test aimed to evaluate the usability of the tool and check if users can use it without any prior training. Secondly, the user acceptance was evaluated through a survey conducted among 180 users of the ViSH platform.

(2) The quality and learning effectiveness of the created Learning Objects. First, the quality of a large sample of Learning Objects created with ViSH Editor and published in the ViSH platform was evaluated by a group of reviewers using LORI (Learning Object Review Instrument) [47]. Then, learning effectiveness was evaluated in two different scenarios. On the one hand, the WBLT-S (WBLT Evaluation Scale for Students) $[48,49]$ instrument was used by learners who had used Learning Objects in the ViSH platform to assess their effectiveness. On the other hand, a study was conducted in a public secondary school to evaluate the effectiveness in terms of student engagement and academic performance of five Learning Objects created with ViSH Editor.

(3) The reusability of the created Learning Objects. First, the LORI instrument was used by reviewers to assess reusability criteria. Then, a set of five metadata quality metrics were used to measure the metadata quality of the Learning Objects. Lastly, a quantitative analysis of reuse in the ViSH platform was conducted in order to provide empirical evidence of the reuse of the Learning Objects created with ViSH Editor.

The results of the evaluation of the first, second, and third factor are shown, respectively, in the Sections Evaluation of the Authoring Tool, Evaluation of the Created Learning Objects, and Reusability Evaluation of the Created Learning Objects. Finally, the research question is answered in Section Conclusions and Future Work where the conclusions of the study are presented. 


\section{EVALUATION OF THE AUTHORING TOOL}

\section{Usability Evaluation}

A lab test with 12 participants was conducted in order to evaluate the usability of the ViSH Editor authoring tool. The lab test involves a one-on-one session between a moderator (usability specialist) and each of the participants. The moderator gives the participants a set of tasks to perform on the system in question and asks them to think aloud while they complete the tasks. A total of 12 people participated in the lab test, eight males and four females, 21-59 years of age $(M=32.6, S D=12.7)$. Five of the participants were teachers, three were engineers, and four were undergraduate students. Participants were requested to perform five representative tasks using the ViSH Editor tool. Each participant performed the tasks in a specific order to avoid carryover effects. Participants did not receive help or support from the moderator. After each task participants had to indicate their emotions with the use of expressive cartoon figures and the intensity of each of these emotions on a scale from 1 to 5 . In this evaluation we used the cartoon figures provided by the LEMtool [50], which express four positive (joy, desire, fascination, satisfaction), and four negative (sadness, disgust, boredom, dissatisfaction) emotions using facial expressions and body postures. The screen and audio were recorded in every lab session so that they could be post processed to measure the task times and number of mouse clicks. Besides, recordings allow hearing what was exactly said in every moment. After completing all the tasks, each participant filled out a SUS (System Usability Scale) [51] questionnaire. The SUS questionnaire consists of 10 questions to be answered in a 5 point Likert scale and yields an overall score on a $0-100$ scale. Lab sessions lasted around $45 \mathrm{~min}$ each. Lastly, in order to measure learnability, three of the participants attended two more sessions in which they performed again the same five tasks. Thereby, each of these participants performed three trials. The time between trials was one day.

The following usability metrics were collected from the lab test. A score for each metric was calculated. All scores are expressed in a $0-100$ scale.

- Task Completion: score was calculated as the percentage of tasks successfully performed by the participants within a specific amount of time and with no errors.

- Task Efficiency: score was calculated as the time spent by the participants on performing the tasks in comparison with the time spent by an expert. The time required by an expert was estimated by measuring and averaging the time spent by two users with extensive expertise using ViSH Editor on performing the tasks of the usability test.

- Clicks Efficiency: score was calculated as the number of mouse clicks required by participants to accomplish the tasks in comparison with the minimum number of mouse clicks required.

- Learnability: score was calculated as the average of the improvements of the Task Completion, Task Efficiency, and Clicks Efficiency scores between the last and first trial performed by three of the participants in comparison with the maximum improvement that could be achieved.

- Task Satisfaction: score was calculated based on the emotions reported by the participants. The intensity of each emotion was reported in a $1-5$ scale. Positive emotions increase the value of the score while negative emotions reduce it.

- Overall satisfaction: score was obtained from the SUS questionnaires filled by the participants.

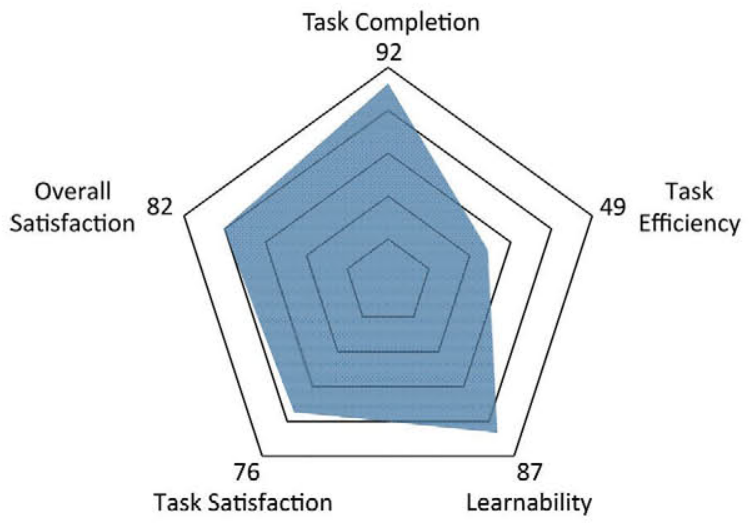

Figure 4 Usability metrics scores of ViSH Editor obtained in the usability evaluation.

The main results of the usability evaluation are exposed in Figure 4. The variations of the scores of the different performance metrics across trials used for calculating the learnability are shown in Figure 5.

Participants succeeded in performing the tasks within the required time and were satisfied with their performance on the tasks as well as with the usability of the tool. The value of 49 obtained in the Task Efficiency metric score indicates that participants in the first trial required on average approximately the double of time than an expert to successfully accomplish the tasks. However, the results also show that efficiency metrics scores notably improve after the first trial. Participants who attended several sessions obtained a Task Efficiency score of 87 and 95 in the second and third trial, respectively. The obtained Learnability metric score points out that little time and effort is needed for becoming proficient with ViSH Editor. Summarizing, the results of the evaluation were very positive and indicated that ViSH Editor is easy and pleasant to use and that authors can use it without any prior training. These results can be considered highly reliable since the usability study involved 12 participants, which is a suitable number when the lab test usability method is used [52]. To date, there are hardly any studies that have quantitatively measured the usability of Learning Object authoring tools. One exception is the usability evaluation carried out in [24] with six users, where the GLO Maker tool achieved a task success rate around $90 \%$. In this evaluation ViSH Editor achieved a task success rate of $92 \%$. Although these results cannot be compared due to the differences between the tasks, there is a consensus that authoring tools that obtain high scores on usability metrics such as task success rate can be considered as easy to use.

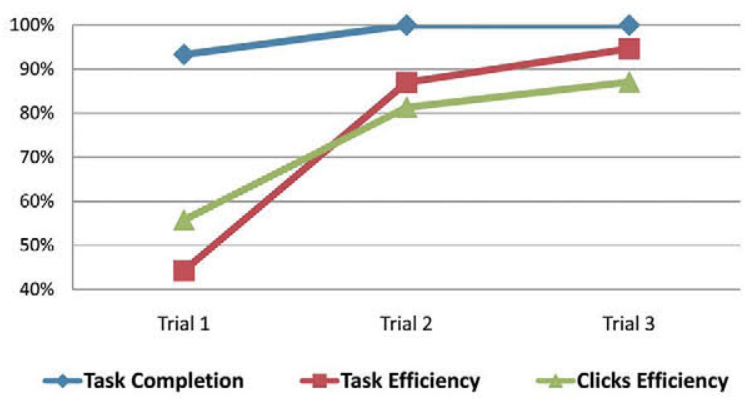

Figure 5 Learnability of ViSH Editor: performance metrics scores across trials. 


\section{Evaluation of the User Acceptance}

An online survey was conducted among the users of the ViSH platform to gather general feedback about the ViSH Editor authoring tool. An email with the link to the survey was sent to all ViSH users that had used ViSH Editor to create and publish at least one Learning Object. Besides, a link to the survey was also included in the "About" section of the tool. A total of 180 surveys were collected. The sample consisted of 180 authors, $44 \%$ males and $56 \%$ females, $18-65$ years of age $(M=40.2, S D=11.7)$. Table 1 shows the results of the survey including for each question the number of responses $(N)$, the mean value $(M)$, and the standard deviation $(S D)$. Some questions of the survey were related to concrete features of ViSH Editor. Each of these questions was answered only by the users who have used the corresponding feature and therefore, in these cases the number of responses differs from the number of respondents.

These results show that ViSH Editor has a high user acceptance among the users of the ViSH community. Overall opinion recorded a mean of 4 in a $1-5$ scale and $93.3 \%$ of the users answered that they would recommend the tool to others. Authors found the tool easy to use and were satisfied with the usefulness of the Learning Objects created. Besides, authors feel that the different features offered by the tool were suitable. Since the combination of different types of content is a characteristic of successful Learning Objects [53], it is important for Learning Object authoring tools to offer suitable features for that. In this case, authors were satisfied with the features provided by ViSH Editor to add and combine text, multimedia resources, websites, own files, and quizzes. The creation of quizzes seems to be a key feature since they allow to effectively enhance the quality of the Learning Objects [54]. Authors were also satisfied with the features for creating novel Learning Objects (i.e. Flashcards, Virtual Tours, and Enriched Videos). They stated that creating new and innovative resources was very useful. Lastly, the results obtained by the features for

Table 1 Results of the ViSH Editor Survey Among Users of the ViSH Platform

\begin{tabular}{|c|c|c|c|}
\hline Question & $N$ & $M$ & $S D$ \\
\hline $\begin{array}{l}\text { Previous experience with Authoring Tools } \\
1 \text { (None) }-5 \text { (A lot) }\end{array}$ & 180 & 3.7 & 1.1 \\
\hline $\begin{array}{l}\text { What is your overall opinion of ViSH Editor? } \\
1 \text { (awful) }-5 \text { (excellent) }\end{array}$ & 180 & 4.0 & 0.5 \\
\hline $\begin{array}{l}\text { How would you describe the experience of learning } \\
\text { to use ViSH Editor? } \\
1 \text { (very difficult) }-5 \text { (very easy) }\end{array}$ & 180 & 4.0 & 0.9 \\
\hline $\begin{array}{l}\text { Please rate the usefulness of the Interactive } \\
\text { Presentations created with ViSH Editor } \\
1 \text { (not useful) }-5 \text { (very useful) }\end{array}$ & 180 & 4.4 & 0.8 \\
\hline \multicolumn{4}{|c|}{$\begin{array}{l}\text { Please rate your overall experience using various features of ViSH Editor } \\
1 \text { (awful) }-5 \text { (excellent) }\end{array}$} \\
\hline Writing text & 175 & 3.9 & 0.9 \\
\hline Adding multimedia resources & 177 & 4.1 & 0.9 \\
\hline Adding websites & 162 & 4.1 & 0.9 \\
\hline Uploading your own files & 168 & 4.0 & 0.9 \\
\hline Creating quizzes & 142 & 3.8 & 1.0 \\
\hline Creati & 126 & 3.9 & 1.1 \\
\hline Creating virtual tours & 132 & 3.8 & 1.1 \\
\hline Creating enriched videos & 116 & 3.8 & 1.0 \\
\hline I Editor Learning Objec & 128 & 4.1 & 0.9 \\
\hline Importing slideshows from PDF files & 141 & 4.0 & 1.0 \\
\hline Help and walkthroughs & 155 & 4.0 & 0.9 \\
\hline Would you recommend ViSH Editor to others? & 180 & $\begin{array}{l}\text { Yes } \\
93.3 \%\end{array}$ & $\begin{array}{l}\text { No } \\
6.7 \%\end{array}$ \\
\hline
\end{tabular}

importing and integrating Learning Objects indicate that authors were able to reuse Learning Objects in an effective way.

\section{EVALUATION OF THE CREATED LEARNING OBJECTS}

\section{Quality Evaluation}

ViSH has a team of reviewers who evaluate the Learning Objects published in the platform using the LORI instrument [47] through a web platform called LOEP [55]. A total of 18 reviewers participated in the evaluations of this study: six e-Learning experts, nine educators, and three designers. Reviewers used the version 1.5 of LORI which considers the nine criteria (or LORI items) listed in Table 2. When using LORI, reviewers have to rate each item using a 5-point scale. A total of 316 Learning Objects created with ViSH Editor were evaluated using LORI. Each of them was evaluated by at least three reviewers generating a total amount of 1,045 evaluations (3.3 evaluations per Learning Object on average). Quality scores were calculated in a $0-10$ scale according to the "LORI Weighted Arithmetic Mean" metric proposed and validated in [56]. This metric calculates the score of a Learning Object as the weighted arithmetic mean of all LORI items scores, giving different importance to each criterion. The weights were obtained through a survey among the ViSH reviewers. When a Learning Object is scored higher or equal to 5 it can be considered of high enough quality to be used for education [56]. Table 2 shows the main results of the LORI evaluations. Figure 6 shows the histogram of the quality scores obtained by the Learning Objects according to the "LORI Weighted Arithmetic Mean" metric.

Learning Objects created with ViSH Editor and published in the ViSH platform obtained satisfactory average scores on all criteria as well as a good average overall quality score $(M=6.1$, $S D=1.7$ ) from the reviewers who evaluated them using LORI. The "Feedback and Adaptation" $(M=2.7, S D=1.0)$ criterion was the only one which recorded a mean below the midpoint of the scale. This indicates that although ViSHEditor provides powerful features to provide feedback and adaptation such as quizzes and the integration of adaptive Learning Objects, some authors do not use them regularly. This also points out that more work could be done for facilitating the creation of adaptive contents. The "Interaction Usability" ( $M=3.3, S D=0.8)$ criterion indicate that ViSH Editor was able to allow authors to create interactive and easy to use Learning Objects. However, the value obtained was moderate and this brings to light that some authors are not taking full advantage of the features to integrate interactive resources. Histogram of LORI quality scores shows that there are Learning Objects with very

Table 2 Average Quality Scores of ViSH Editor Learning Objects Based on LORI $(\mathrm{N}=316)$

\begin{tabular}{lcc}
\hline & $M$ & $S D$ \\
\hline Overall score (LORI weighted arithmetic mean quality metric) & 6.1 & 1.7 \\
0-10 & & \\
LORI items 1-5 & 3.7 & 0.9 \\
1. Content quality & 3.7 & 0.9 \\
2. Learning goal alignment & 2.7 & 1.0 \\
3. Feedback and adaptation & 3.5 & 0.9 \\
4. Motivation & 3.3 & 0.9 \\
5. Presentation design & 3.3 & 0.8 \\
6. Interaction usability & 3.4 & 0.7 \\
7. Accessibility & 3.2 & 0.9 \\
8. Reusability & 4.5 & 0.4 \\
9. Standards compliance & &
\end{tabular}




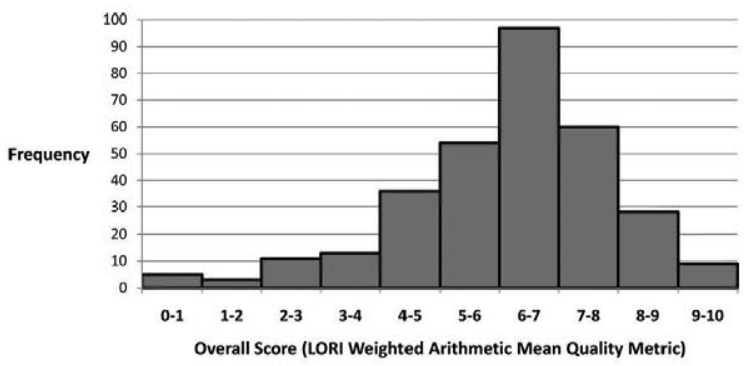

Figure 6 Histogram of LORI quality scores obtained by ViSH Editor Learning Objects.

different quality scores. Nevertheless, around $80 \%$ of the Learning Objects were scored higher than 5 . This evidence points out that although authoring tools like ViSH Editor can facilitate authors the creation of high quality Learning Objects they cannot guarantee it.

\section{Effectiveness Evaluation in a Repository of Open Educational Resources}

Learning Objects published in the ViSH platform are also evaluated by end users using WBLT-S $[48,49]$. WBLT-S allows assessing the effectiveness as educational resources of the Learning Objects from a learner's perspective. It considers the 13 criteria listed on Table 3. In ViSH, learners use a version of WBLT-S provided by the LOEP system which has a 7-point Likert scale. A total of 72 Learning Objects created with ViSH Editor were evaluated by learners through WBLT-S generating a total amount of 909 evaluations (12.6 evaluations per Learning Object on average). Scores were calculated in a 0-10 scale using an arithmetic mean metric. Thereby, the score of each Learning Object was calculated as the arithmetic mean of all WBLT-S criteria scores converted to a $0-10$ scale. Table 3 shows the main results of the evaluations. Figure 7 shows the histogram of the scores obtained by the Learning Objects based on the WBLT-S evaluations.

Learning Objects created with ViSH Editor and published in the ViSH platform obtained satisfactory average scores on all criteria as well as a good average overall score $(M=7.8, S D=1.7)$ from the learners who evaluate them using WBLT-S. WBLT-S evaluations show that learners found the Learning Objects very engaging, beneficial for their learning, and easy to use. Besides,

Table 3 Average Learners' Scores of ViSH Editor Learning Objects Based on WBLT-S $(\mathrm{N}=72)$

\begin{tabular}{|c|c|c|}
\hline & $M$ & $S D$ \\
\hline Overall score (WBLT-S arithmetic mean quality metric) $0-10$ & 7.8 & 1.7 \\
\hline \multicolumn{3}{|l|}{ WBLT-S criteria $1-7$} \\
\hline 1. The learning object was well organized & 5.9 & 1.1 \\
\hline 2. The learning object was easy to use & 6.0 & 1.1 \\
\hline 3. The instructions in the learning object were easy to follow & 5.7 & 1.3 \\
\hline 4. The help features of the learning object were useful & 5.5 & 1.3 \\
\hline learning object helped me learn & 5.8 & 1.3 \\
\hline 6. The feedback from the learning object helped me learn & 5.2 & 1.4 \\
\hline $\begin{array}{l}\text { 7. The graphics and animations from the learning object } \\
\text { helped me learn }\end{array}$ & 5.6 & 1.2 \\
\hline 8. The learning object helped teach me a new concept & 5.7 & 1.2 \\
\hline 9. Overall, the learning object helped me learn & 5.8 & 1.4 \\
\hline 10. I like the over & 5.9 & 1.4 \\
\hline 11. I found the learning object to be engaging & 5.6 & 1.3 \\
\hline 12. The learning & 5.4 & 1.3 \\
\hline 13. I would like to use learning objects like this again & 6.0 & 1.3 \\
\hline
\end{tabular}

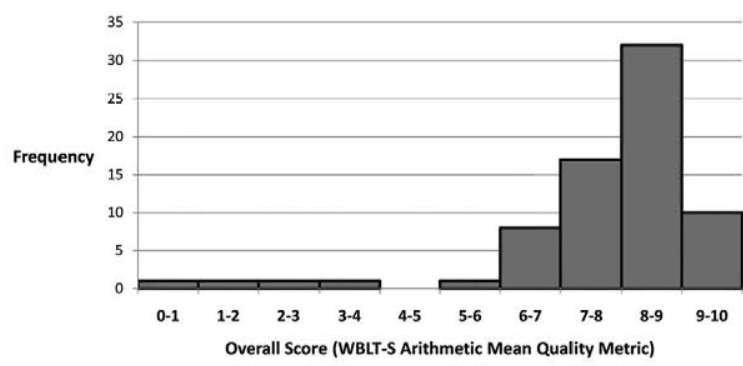

Figure 7 Histogram of WBLT-S scores obtained by ViSH Editor Learning Objects.

learners indicated that they would like to use Learning Objects in more occasions. Graphics and animations were scored satisfactorily pointing out that ViSH Editor allowed authors to effectively integrate this type of resources in their Learning Objects. The score obtained by the feedback criterion indicates that the tool was also effective in supporting authors to add quizzes and importing other assessment resources. Histogram of WBLT-S scores shows that around $95 \%$ of the Learning Objects were scored higher than 5. Thus, it can be stated that the tool has proven to be able to allow users to create Learning Objects effective from the learners' perspective.

\section{Effectiveness Evaluation in a Classroom Environment}

A study was conducted in a public secondary school in order to evaluate the learning effectiveness in terms of engagement and academic performance of the Learning Objects created with ViSH Editor.

A total of 38 12th grade students participated in the study, 16 males and 22 females, $17-18$ years of age $(M=17.2, S D=0.6)$. Students took a teaching unit about Internet and computer networks in a 12th grade subject called "Information and Communication Technologies". The teaching unit was completed in five 2-h lessons ( $10 \mathrm{~h}$ in total), which were conducted in a computer lab with Internet connection. In each lesson, students used one Learning Object created with ViSH Editor. Therefore, five Learning Objects were used in total. Students accessed to the Learning Objects directly on the ViSH web portal. The teacher was present, encouraged students to pursue the learning activities, and provided clarification to the students when it was necessary, but students learned the contents exclusively from the Learning Objects. After each lesson, the Learning Object used in that lesson was evaluated by the students through WBLT-S $[48,49]$ and by the teacher through WBLT-T (WBLT Evaluation Scale for Teachers) [49]. WBLT-T is a scale similar to WBLT-S but intended to be used by teachers in order to allow them to evaluate the effectiveness of the Learning Objects they employed in their lectures. Thus, the five Learning Objects used in the teaching unit were evaluated by the 38 students generating 190 WBLT-S evaluations and by the teacher generating five WBLT-T evaluations. Tables 4 and 5 show, respectively, the results of the students' evaluations and of the teacher's evaluations. For each student and the teacher, the score of each criterion was calculated by averaging the scores given to the five Learning Objects used in the lessons. Standard deviation is included in Table 4 to show the variation among students' scores but not in Table 5 since WBLT-T evaluations were carried out by a single teacher. Finally, after completing the five lessons, students took an exam on paper about the concepts presented in the teaching unit. 
Table 4 Average Students' Scores of the Learning Objects Used Based on WBLT-S $(\mathrm{N}=38$ )

\begin{tabular}{lll}
\hline & $M$ & $S D$ \\
\hline Overall score (WBLT-S arithmetic mean quality metric) $0-10$ & 8.1 & 1.8 \\
WBLT-S criteria 1-7 & & \\
1. The learning object was well organized & 5.8 & 1.3 \\
2. The learning object was easy to use & 6.0 & 1.2 \\
3. The instructions in the learning object were easy to follow & 5.9 & 1.3 \\
4. The help features of the learning object were useful & 6.0 & 1.2 \\
5. Working with the learning object helped me learn & 5.9 & 1.1 \\
6. The feedback from the learning object helped me learn & 5.9 & 1.2 \\
7. The graphics and animations from the learning object & 5.9 & 1.2 \\
helped me learn & & \\
8. The learning object helped teach me a new concept & 5.9 & 1.2 \\
9. Overall, the learning object helped me learn & 6.0 & 1.1 \\
10. I like the overall theme of the learning object & 5.8 & 1.1 \\
11. I found the learning object to be engaging & 5.9 & 1.2 \\
12. The learning object made learning fun & 5.8 & 1.2 \\
13. I would like to use learning objects like this again & 5.9 & 1.3 \\
\hline
\end{tabular}

Students' exam scores recorded a mean of 9.2 out of 10 with a standard deviation of $0.9(M=9.2, S D=0.9)$. The minimum score was 6.0 , so all students passed.

The results of this study show that both students and the teacher were very satisfied with the Learning Objects created through ViSH Editor that were used in the teaching unit. Learning Objects were perceived as easy to use and useful for teaching and learning. Besides, Learning Objects were able to engage and motivate the students. Therefore, it is not surprising that students reported that they would like to use similar learning resources in more occasions. The learning outcomes achieved by the students were outstanding showing that ViSH Editor Learning Objects can be very effective in terms of learner performance. According to [57], the effectiveness of virtual learning programs can be classified into eight areas based on the learner satisfaction and performance. Considering the average overall WBLT-S score (8.1) as learner satisfaction and the average of students' exam scores as learner performance (9.2), the effectiveness obtained in this study can be classified as "high effective." It can be concluded, therefore, that ViSH Editor allows teachers to create effective Learning Objects.

Table 5 Average Teacher's Scores of the Learning Objects Used Based on WBLT-T $(\mathrm{N}=1)$

\begin{tabular}{lc}
\hline & $M$ \\
\hline Overall Score (WBLT-T arithmetic mean quality metric) 0-10 & 9.5 \\
WBLT-T criteria 1-7 & 7.0 \\
1. The learning object was easy for me to use & 6.6 \\
2. The learning object was easy for students to use & 6.8 \\
3. The students found the learning object instructions clear & \\
4. The graphics and animations from the learning object helped & 7.0 \\
students learn & 7.0 \\
5. The learning object enhanced student learning & 6.8 \\
6. The learning object helped clarify the concept(s) being taught & 6.8 \\
7. Overall, it was beneficial to me the learning object for teaching & 6.8 \\
8. The students were on task or focused when the learning object & 6.8 \\
was being used & \\
9. The students liked the interactive quality of the learning object & 6.4 \\
10. The students appeared to like the learning object & 6.2 \\
11. Overall, the students were engaged when the learning object & 6.2 \\
was being used & \\
\hline
\end{tabular}

\section{REUSABILITY EVALUATION OF THE CREATED LEARNING OBJECTS}

\section{Quality Evaluation from a Reusability Perspective}

The ViSH reviewers team who evaluate the Learning Objects published in the platform using the LORI instrument [47] rate their accessibility, reusability, and standards compliance. Accessibility takes into account if the Learning Objects can be accessed from portable devices, reusability (as defined in LORI) assess the ability of the Learning Objects to be used in varying learning contexts and with learners from differing backgrounds, and standards compliance assess the adherence of the Learning Objects to e-Learning standards and specifications. Thus, the evaluation of these three criteria provides a measure of the capacity of the Learning Objects to be reused in different e-Learning systems and educational environments. The results of the LORI evaluations are shown in Table 2. Reviewers rated Learning Objects positively in terms of "Accessibility" $(M=3.4, S D=0.7)$, "Reusability" $(M=3.2,0.9)$ and "Standards Compliance" $(M=4.5,0.4)$. The high score obtained by the "Standards Compliance" criterion is because all Learning Objects created with the tool can be exported to SCORM 1.2 and SCORM 2004, and are tagged with LOM compliant metadata. In summary, these results indicate that ViSH Editor allows creating Learning Objects with suitable characteristics to facilitate their reuse in different contexts and e-Learning systems.

\section{Metadata Evaluation}

The evaluation of metadata is important in order to assess reusability because the more complete the metadata of a Learning Object are, the higher is its capacity to be found and reused [36]. In the ViSH platform, metadata quality is measured by using a set of five metadata quality metrics: "Completeness", "Conformance", "Consistency", "Coherence", and "Findability". These metrics are fully explained in [6]. ViSH automatically calculates the metadata quality scores in a 0-10 scale for all published Learning Objects based on their metadata using these metrics particularized for the LOM standard and the ViSH repository. Besides, an overall metadata quality score is calculated in a $0-10$ scale as the arithmetic mean of all previous scores. Metadata quality scores were calculated for 1,486 Learning Objects created with ViSH Editor. Table 6 shows these metadata quality scores and Figure 8 shows their histogram.

Results show that authors tagged most of the Learning Objects using ViSH Editor with good metadata $(M=6.3$, $S D=1.3$ ) in terms of completeness, conformance, consistency, coherence, and findability. Histogram of metadata quality scores shows that metadata of around $82 \%$ of the Learning Objects recorded scores higher than 5 out of 10 . The "Completeness" score ( $M=7.1, S D=1.3$ ) indicates that, in general, metadata contain enough information to have a comprehensive description of the Learning Objects. The "Conformance" score $(M=6.5, S D=1.1)$ points out that metadata are considerably useful for users in order to find, identify, and select Learning Objects. The score obtained for the "Consistency" metric $(M=10.0, S D=0.0)$ proves that metadata generated by ViSH Editor fully adhere to the LOM standard. For metrics "Coherence" and "Findability", average scores below 5 out of 10 were obtained together with high standard deviations. This is because authors did not tag some Learning Objects with important metadata such as their descriptions and keywords, and therefore, the obtained coherence and findability 
Table 6 Average Metadata Quality Scores of ViSH Editor Learning Objects $(\mathrm{N}=1,486)$

\begin{tabular}{|c|c|c|}
\hline & M & $S D$ \\
\hline Overall metadata quality score $0-10$ & 6.3 & 1.3 \\
\hline \multicolumn{3}{|l|}{ Metadata quality scores $0-10$} \\
\hline $\begin{array}{l}\text { 1. Completeness: degree to which the metadata instance } \\
\text { contains all the information needed to have a } \\
\text { comprehensive representation of the described resource. }\end{array}$ & 7.1 & 1.3 \\
\hline $\begin{array}{l}\text { 2. Conformance: degree to which the metadata instance } \\
\text { fulfills the requirements of a given community of users } \\
\text { for a given set of tasks: find, identify, and select. }\end{array}$ & 6.5 & 1.1 \\
\hline $\begin{array}{l}\text { 3. Consitency: degree to which the metadata instance } \\
\text { matches the LOM metadata standard definition. }\end{array}$ & 10 & 0.0 \\
\hline $\begin{array}{l}\text { 4. Coherence: degree to which all the fields of the metadata } \\
\text { instance describe the same object in a similar way. }\end{array}$ & 4.8 & 4.0 \\
\hline $\begin{array}{l}\text { 5. Findability: ease with which the metadata instance can } \\
\text { be found. }\end{array}$ & 3.2 & 3.9 \\
\hline
\end{tabular}

scores for those resources were 0. Learning Objects tagged with these metadata fields recorded significantly better "Coherence" $(M=7.1, S D=2.7)$ and "Findability" $(M=6.3, S D=3.5)$ scores. In conclusion, it can be stated that ViSH Editor allows creating Learning Objects with appropriate metadata.

\section{Quantitative Analysis of Reuse in a Repository of Open Educational Resources}

In order to provide empirical evidence of the reuse of the Learning Objects created with ViSH Editor, a quantitative analysis of reuse was conducted in the ViSH platform. Results are shown in Table 7. Data corresponds to the period from April 2012 to June 2016 except the number of learning hours delivered which is provided since August 2014, date in which the tracking system of ViSH started to operate. The number of learning hours delivered represents the number of hours that users have spent interacting with ViSH Editor Learning Objects in the ViSH platform or in other Virtual Learning Environments. Only sessions with significant interactions from learners are taken into account for calculating delivered learning hours. Ratios of two different types of reuse were calculated. On the one hand, the percentage of Learning Objects reused to create new ones was calculated as the number of ViSH Editor Learning Objects hosted in ViSH that had been reused to create or enrich other ViSH Editor Learning Objects compared to the total number of ViSH Editor Learning Objects in the repository. On the other hand, the percentage of Learning Objects reused in collections was calculated as the number of ViSH Editor Learning Objects hosted in ViSH that had

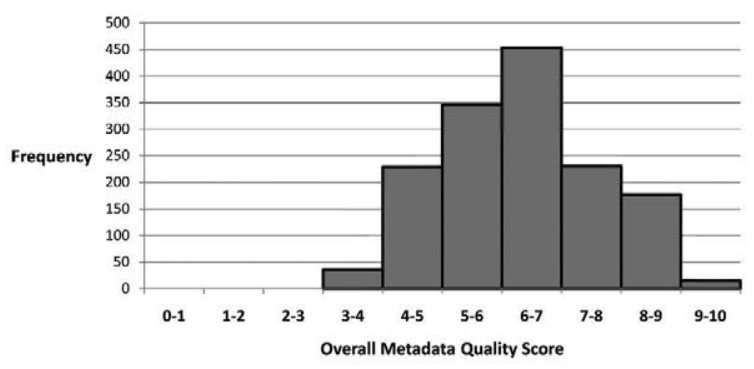

Figure 8 Histogram of metadata quality scores obtained by ViSH Editor Learning Objects.
Table 7 Usage Statistics of Learning Objects Created with ViSH Editor in the ViSH Platform

\begin{tabular}{ll}
\hline Number of Learning Objects created & 2,594 \\
Number of learning hours delivered & 64,984 \\
Number of visits & $1,133,206$ \\
Number of downloads & 145,365 \\
Percentage of Learning Objects reused to create new & $12.0 \%$ \\
$\quad$ Learning Objects & \\
Percentage of Learning Objects reused in collections & $33.5 \%$ \\
\hline
\end{tabular}

been saved by at least one user into a collection compared to the total number of ViSH Editor Learning Objects in the repository.

A total of 2,594 Learning Objects have been created by ViSH users through ViSH Editor. These resources have delivered around 64,984h of learning since August 2014 (around $95 \mathrm{~h}$ per day), have received more than one million of visits and have been downloaded around 145,000 times. The percentage of Learning Objects reused to create new ones was $12 \%$. This result is quite similar to the $11.5 \%$ obtained in the quantitative analysis of reuse conducted by Ochoa [6] in ARIADNE. Our results also show that around one of every three Learning Objects was reused in collections. This ratio of reuse is notably higher than those obtained by previous research [6,7], in which ratios of reuse of around $23 \%$ and $19 \%$ were found, respectively in the repositories Connexions and LRE. Taking into account this empirical evidence, the results obtained in the LORI evaluations where the accessibility, reusability, and standards compliance of the Learning Objects were assessed, and the metadata quality scores calculated, it can be stated that ViSH Editor is capable of creating Learning Objects with a high reusability that can be easily shared and distributed.

\section{CONCLUSIONS AND FUTURE WORK}

This paper presents ViSH Editor, an easy to use open source webbased authoring tool to create effective and reusable Learning Objects. A complete evaluation of the tool has been conducted addressing three key factors: the usability and user acceptance of the authoring tool, the quality and learning effectiveness of the created Learning Objects, and the reusability of these resources. The results of the usability evaluation indicated that ViSH Editor is easy and pleasant to use and that authors can use the tool without any prior training and need little time and effort for becoming proficient with it. A survey conducted among 180 users revealed a high user acceptance of the tool. The evaluations of quality and learning effectiveness proved that the tool is able to allow users to create Learning Objects with high quality and effective in terms of learner engagement and academic performance. Finally, the reusability evaluation indicated that ViSH Editor is capable of creating Learning Objects with a high reusability that can be easily shared and distributed. Based on the results of these evaluations, and in answer to the research question of the study, we conclude that ViSH Editor is an authoring tool capable of allowing educators to create effective and reusable Learning Objects in an easy way. Besides, the tool is distributed under an open source license, which is a requirement that some researchers have indicated that a Learning Object authoring tool should meet [13].

The present paper makes an important contribution by providing evidence that educators can create effective and reusable Learning Objects in an easy way if they are provided with suitable authoring tools. It also identifies several characteristics that should 
be considered in the implementation of such tools. Therefore, results of this study can drive future development of better Learning Object authoring tools. In order for the strategy of creating Learning Objects using authoring tools to be successful, these tools need to be easy to use and able to create effective Learning Objects with high reusability. Nevertheless, there is no authoring tool that can guarantee that the educational resources it creates have a suitable quality and learning effectiveness, although they can help to make this happen. Although there are some works in the literature that have described and evaluated open source Learning Object authoring tools [15-24], none of them have performed an evaluation addressing all the aspects evaluated in this study. Therefore, this work can be useful for developers and other researchers interested in evaluating Learning Object authoring systems. Besides, the evaluation of a Learning Object authoring tool in the context of a repository of open educational resources also constitutes a novel contribution.

We plan to further improve the authoring tool and extend it with new features to support the XAPI e-Learning standard, create more interactive Learning Objects such as 3D Flashcards or augmented reality resources and facilitate the creation of adaptive Learning Objects capable of tailoring their behaviour according to the learners' profile. Finally, we make a call for further research to examine the use of Learning Objects created with different systems in various educational environments to investigate how to use Learning Objects in a more effective way, and to identify new features that can be useful for authoring tools in order to produce more effective and reusable Learning Objects.

\section{REFERENCES}

D. A. Wiley, Learning Object Design and Sequencing Theory. Brigham Young University, 2000.

J. Sinclair, M. Joy, J. Yin-Kim Yau, and S. Hagan, A practiceOriented review of learning objects, IEEE T Learn Technol 6 (2013), 177-192.

A. Baki and Ü. Çakıroğlu, Learning objects in high school mathematics classrooms: Implementation and evaluation, Comput Educ 55 (2010), 1459-1469.

R. Kay, Exploring the use of web-based learning tools in secondary school classrooms, Interact Learn Envir 22 (2014), 67-83.

L. Siong Hoe and P. C. Woods, Developing object-based learning environment to promote learners' motivation for learning digital systems, Comput Appl Eng Educ 18 (2010), 640-650.

X. Ochoa, Learnometrics: Metrics for Learning Objects. Katholieke Universiteit Leuven, 2008.

R. Vuorikari and R. Koper, Evidence of cross-boundary use and reuse of digital educational resources, Int J Emer Technol Lear 4 (2008), 51-56.

R. Kay, L. Knaack, and D. Petrarca, Exploring teachers perceptions of web-based learning tools, Interdiscip J E-Learn Obj 5 (2009), 27-50. N. Y. Yen, T. K. Shih, L. R. Chao, and Q. Jin, Ranking metrics and search guidance for learning object repository, IEEE T Learn Technol 3 (2010), 250-264.

H. Drachsler, K. Verbert, O. Santos, and N. Manouselis, Panorama of recommender systems to support learning. In: Recommender systems handbook. F. Ricci, L. Rokach, and B. Shapira (Eds.), Springer, US, 2015, pp 421-451.

B. de los Arcos, R. Farrow, L.-A. Perryman, R. Pitt, and M. Weller, OER Evidence Report 2013-2014, OER Research Hub, 2014.

S. Ainsworth and P. Fleming, Evaluating authoring tools for teachers as instructional designers, Comput Human Behav 22 (2006), $131-148$.
P. E. Battistella, A. von Wangenheim, and C. G. von Wangenheim, Evaluation of free authoring tools for producing learning objects on SCORM, IEEE Multidiscip Engr Educ Mag 5 (2010), 15-26.

C. Coppola and E. Neelley, Open source - opens learning: Why open source makes sense for education, R-Smart Group (2004).

A. Koohang, K. Floyd, and C. Stewart, Design of an open source learning objects authoring tool - the LO creator, Interdiscip J E-Learn Obj 7 (2011), 111-123.

T. Boyle, Generative learning objects (GLOs): Design as the basis for reuse and repurposing, First International Conference of e-Learning and Distance Education, 2009.

J. Watson, A. Dickens, and G. Gilchrist, The LOC tool: creating a learning object authoring tool for teachers, Proceedings of Ed-Media 2008: World Conference on Educational Multimedia, Hypermedia \& Telecommunications, 2008.

V. Gonzalez-Barbone and L. Anido-Rifon, Creating the first SCORM object, Comput Educ 51 (2008), 1634-1647.

C. D. Milligan, P. Beauvoir, and P. Sharples, The reload learning design tools, J Inc Media Educ (2005).

L. Gonzalez, M. Mashat, and S. Romero, Creating and updating models of activities for people with alzheimer disease using JClic platform, Proceedings of the 7th International Conference on Pervasive Computing Technologies for Healthcare and Workshops, Venice, Italy, 2013, pp 356-361.

S. Ball and J. Tenney, Xerte - a user-Friendly tool for creating accessible learning objects. In: Computers helping people with special needs. K. Miesenberger, J. Klaus, W. Zagler, and A. Karshmer (Eds.), Springer, Berlin Heidelberg, 2008, pp 291-294.

M. Stanescu and M. Stoicescu, Study about the efficiency of webbased tools used for physical education teachers' training, Proceedings of the 9th International Scientific Conference eLearning and Software for Education, Bucharest, Romania, 2013.

C. Gonçalo and A. A. Amorim, Development of Learning Objects for Library and Information Sciences by Postgraduate Students, 2012 IEEE International Symposium on Computers in Education (SIIE), 2012.

F. Dağ, L. Durdu, and S. Gerdan, Evaluation of educational authoring tools for teachers stressing of perceived usability features, Procedia Soc Behav Sci 116 (2014), 888-901.

A. L. Alice, A. da Costa, and M. F. Vick, Development and evaluation of an authoring tool taxonomy, IEEE Revista Iberoamericana de Tecnologias del Aprendizaje 10 (2015) 204-211.

T. H. Kaskalis, T. D. Tzidamis, and K. Margaritis, Multimedia authoring tools: The quest for an educational package, Educ technol Socy 10 (2007), 135-162.

T. Aleahmad, V. Aleven, and R. Kraut, Creating a corpus of targeted learning resources with a web-based open authoring tool, IEEE T Learn Technol 2 (2009) 3-9.

B. Meixner, K. Matusik, C. Grill, and H. Kosch, Towards an easy to use authoring tool for interactive non-linear video, Multimed Tools Appl 70 (2014), 1251-1276.

eXeLearning. Available from: http://exelearning.net.

JClic. Available from: http://clic.xtec.cat/en.

RELOAD project. Available from: http://www.reload.ac.uk. Xerte. Available from: http://www.xerte.org.uk.

Authoring tools for advanced technology learning environments: Toward cost-effective adaptive, Interactive and intelligent educational software. T. Murray, S. Blessing, and S. Ainsworth (Eds.), Springer, Netherlands, 2003

M. Gaeta, V. Loia, G. R. Mangione, F. Orciuoli, P. Ritrovato, and S. Salemo, A methodology and an authoring tool for creating Complex Learning Objects to support interactive storytelling, Comput Hum Behav 31 (2014), 620-637.

J. Cubillo, S. Martin, M. Castro, and I. Boticki, Preparing augmented reality learning content should be easy: UNED ARLE - An authoring tool for augmented reality learning environments, Comput Appl Eng Educ 23 (2015), 778-789.

P. Zervas and D. G. Sampson, Facilitating teachers' reuse of mobile assisted language learning resources using educational metadata, IEEE T Learn Technol 7 (2014), 6-16. 
D. G. Sampson, P. Zervas, and G. Chloros, Supporting the process of developing and managing LOM application profiles: The ASKLOM-AP tool, IEEE T LearnTechnol 5 (2012), 238-250.

P. Lopez, P. J. Muñoz-Merino, C. Fernandez-Panadero, and C. Delgado, Courseeditor: A course planning tool compatible with IMSLD, Comput Appl Eng Educ 21 (2013), 421-431.

S. Isotani, R. Mizoguchi, S. Isotani, O. M. Capeli, N. Isotani, A. R. P. L. De Albuquerque, I. I. Bittencourt, and P. Jaques, A semantic web-based authoring tool to facilitate the planning of collaborative learning scenarios compliant with learning theories, Comput Educ 63 (2013), 267-284.

F. Hernández-Del-Olmo and E. Gaudioso, Autotest: An educational software application to support teachers in creating tests, Comput Appl Eng Educ 21 (2013), 636-640.

A. Beg, A web-based method for building and simulating standard cell circuits - A classroom application, Comput Appl Eng Educ 23 (2015), 304-313.

M. Derya and Z. Ylldırm, Effectiveness of learning objects in primary school social studies education: Achievement, perceived learning, engagement and usability, Egitim Ve Bilim 39 (2014), 131-143.

T. Leinonen, J. Purma, H. Pöldoja, and T. Toikkanen, Information architecture and design solutions scaffolding authoring of open educational resources, IEEE T Learn Technol 3 (2010), 116-128.

M. Barak and S. Ziv, Wandering: A web-based platform for the creation of location-based interactive learning objects, Comput Educ 62 (2013), 159-170.

G. Elia, G. Secundo, and C. Taurino, The web learning system of 'Virtual eBMS': a tool supporting unstructured and just-in-time learning, Int J Network Virt Org 6 (2009), 140-160.

E. Barra, A. Gordillo, and J. Quemada, Virtual science hub: An open source platform to enrich science teaching, Int J Soc Behav Educ Econ Bus Ind Eng 8 (2014), 741-746.

T. L. Leacock and J. C. Nesbit, A framework for evaluating the quality of multimedia learning resources, Educ Technol Socy 10 (2007), 44-59.
R. Kay, Evaluating learning, design, and engagement in web-based learning tools (WBLTs): The WBLT Evaluation Scale, Comput Hum Behav 27 (2011), 1849-1856.

R. Kay, Examining the effectiveness of web-based learning tools in middle and secondary school science classrooms, Interdiscip J E-Learn Obj 7 (2011), 359-374.

G. Huisman, M. van Hout, E. van Dijk, T. van der Geest, and D. Heylen, LEMtool: Measuring emotions in visual interfaces, Proceedings of the SIGCHI conference on human factors in computing systems, Paris, France, 2013, pp 351-360.

J. Brooke, SUS - A quick and dirty usability scale. In: Usability evaluation in industry. P. W. Jordan, B. Thomas, B. Weerdmeester, and I. L. McClelland (Eds.), CRC Press, USA, 1996, pp 189-194.

T. Tullis and W. Albert, Measuring the user experience: collecting, analyzing, and presenting usability metrics. Morgan Kaufmann, USA, 2008.

R. Schibeci, D. Lake, R. Phillips, K. Lowe, R. Cummings, and E. Miller, Evaluating the use of learning objects in Australian and New Zealand schools, Comput Educ 50 (2008), 271-283.

A. Gordillo, E. Barra, and J. Quemada, Enhancing web-based learning resources with existing and custom quizzes through an authoring tool, IEEE Revista Iberoamericana De Tecnologias Del Aprendizaje 10 (2015), 215-222.

A. Gordillo, E. Barra, and J. Quemada, A flexible open source web platform to facilitate learning object evaluation, Proceedings of the 2014 Frontiers in Education Conference (FIE 2014), Madrid, Spain, 2014.

A. Gordillo, E. Barra, and J. Quemada, Towards a learning object pedagogical quality metric based on the LORI evaluation model, Proceedings of the 2014 Frontiers in Education Conference (FIE 2014), Madrid, Spain, 2014.

A. Fayyoumi and G. Elia, A systemic model for measuring the effectiveness of virtual learning programs, Int J Infor Technol Manage 14 (2015), 305-332. 